\title{
Die implementering van 'n kleinste-kwadrate- algoritme vir die frekwensiebepaling van 'n protonpresessiesein
}

Ontvang 3 Augustus 1995; aanvaar 30 November 1995

\section{UITTREKSEL}

'n Voordelige tegniek vir die frekwensiebepaling van 'n tydbeperkte sinusvormige sein in ruis is geïmplementeer. Dit maak gebruik van die metode van kleinste kwadrate en is veral geskik wanneer die frekwensie in die kortste moontlike tyd (in vergelyking met die seinperiode) bepaal moet word, soos die geval is met byvoorbeeld die presessiesein in 'n protonmagnetometer. Die kriterium vir beoordeling van enige tegniek onder laasgenoemde voorwaarde is die minimum meettyd vir 'n gegewe meetfout of die minimum fout vir 'n gegewe meettyd. Die voorgestelde tegniek word met die konvensionele metode vergelyk en die resultate toon ' $n$ aansienlike verbetering.

\begin{abstract}
The implementation of a least squares algorithm for estimating the frequency of a proton precession signal An advantageous signal processing technique for estimating the frequency of a time-limited noisy sinusoidal signal has been implemented. The method is a least squares technique and is especially powerful when the estimation has to be done in the shortest possible time measured in terms of signal period, as is the case with the precession signal present in a proton magnetometer. The criterion for evaluating the performance is the minimum measuring time for a given error or the minimum error for a given measuring time. This technique is compared with the accepted way of measuring and the results show a considerable improvement.
\end{abstract}

\section{INLEIDING}

Alhoewel hierdie werk aanvanklik daarop gemik was om 'n optimale tegniek te vind vir die onttrekking van die frekwensie-inligting vanuit die presessiesein van die protonmagnetometer, kan hierdie tegniek sekerlik aangewend word in gevalle waar soortgelyke beperkings heers.

Die tipiese protonpresessiesein is sinusvormig met eksponensiële verval te midde van ruis en kan deur die volgende vergelyking voorgestel word ${ }^{1}$ :

$$
S(t)=V e^{-\alpha t} \sin \omega_{s} t+n(t)
$$

waar $\sin \omega_{s} t$ die harmoniese funksie is waarvan die frekwensie bepaal moet word, $V$ is die amplitude van die sein, $\alpha$ is die vervalkonstante en $n(t)$ verteenwoordig die ruisterm, 'n stasionêre, ergodiese noubandproses met 'n gemiddelde waarde $M(n)$ van nul en 'n standaardafwyking $\sigma(n)$. 'n Voorstelling van 'n eksperimenteel-bepaalde protonpresessiesein word getoon in figuur 1 . Figuur l(a) is verkry deur die sein te registreer met ' $n$ tydskaal van 1 s/divisie en toon die eksponensiële verval van die seinamplitude totdat dit in die ruissein verdwyn. Figuur l(b) toon 'n kort gedeelte van die sein op 'n tydskaal van $1 \mathrm{~ms} /$ divisie en die ruismodulasie is duidelik sigbaar.

Die tydkonstante van die eksponensiële funksie in vergelyking met die seinfrekwensie sal bepaal hoeveel seinperiodes beskikbaar is waarbinne die frekwensie of periode bepaal kan word voordat ' $n$ te swak sein/ruis-verhouding die lesings onbetroubaar maak. Vir die geval van die protonpresessie-magnetometer is ' $n$ tipiese frekwensie ongeveer $1 \mathrm{kHz}$ en die meetproses moet binne een seinwaarneming van ongeveer 1 sekonde afgehandel word met die vereiste van

die beste resolusie en akkuraatheid vir hierdie beperkte tyd.

\section{PROBLEEMDEFINISIE}

Die hoofdoel met enige gekose meettegniek sou dus wees om die beste estimasie van die parameter $\omega_{s}$, soos in vergelyking (1) gedefinieer, binne die kortste praktiese waarne-

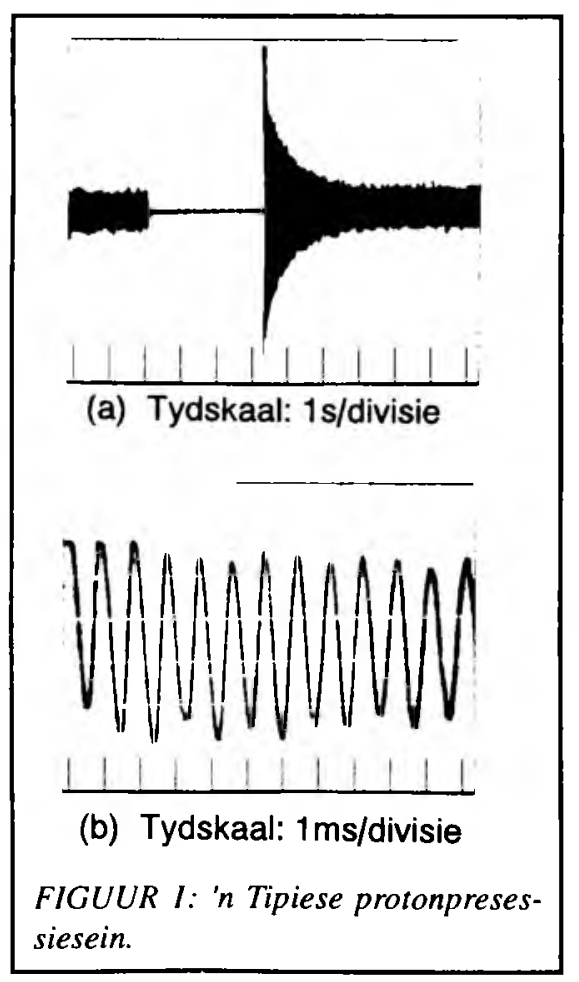


mingstyd (ongeveer 1 sekonde by die protonmagnetometer) te verkry in die teenwoordigheid van ruis. Bogenoemde doelwit kan bereik word deur die ontleding van 'n stel data wat verkry is deur die bepaling van tydwaardes waarop gekose seinvlakke in die funksie $S(t)$ herhaal. Die spesiale geval van positiewe nulkruisings sal vir die doel van hierdie ontleding gebruik word. In die teenwoordigheid van die ruiskomponent $n(t)$ sal die nulkruisings willekeurige modulasie ervaar waarvan die eienskappe 'n funksie sal wees van die ruisparameters.

Die tye waarop die positiewe nulkruisings sal voorkom by die sein sonder ruis vorm die ideale ry $[Z \%$ waarvan die waardes eweredig versprei is:

$$
t_{0}^{0}, t_{1}^{0}, \ldots, t_{p}^{o}, \ldots, t_{N_{s}}^{o}
$$

As gevolg van die additiewe ruiskomponent $n(t)$ sal die posisie van elke punt in laasgenoemde ry verander word deur die volgende willekeurige waardes:

$$
\Delta t_{0}, \Delta t_{1}, \ldots, \Delta t_{p}, \ldots, \Delta t_{N_{s}}
$$

Dit sal dan 'n nie-ideale ry $[Z]$ tot gevolg hê waarvan die punte nie eweredig gespasieer is nie:

$$
t_{0}, t_{1}, \ldots, t_{p}, \ldots, t_{N_{s}}
$$

Die effek van die modulasie van die nulkruisings as gevolg van die additiewe ruissein $n(t)$ kan soos volg vir die $p$-de kruising bereken word:

$$
\Delta t_{p}=t_{p}-t_{p}^{o}
$$

Daar kan aangetoon word' dat die stel van willekeurige waardes in vergelyking (2), soos verkry uit die verwantskap gegee deur vergelyking (4), 'n standaardafwyking het wat soos volg in terme van die sein/ruis-verhouding $\left(R_{S / R}\right)$ uitgedruk kan word:

$$
\sigma\left(\Delta t_{p}\right)=\frac{T_{s}}{2 \sqrt{2} \pi R_{s R}}
$$

waar $\mathrm{T}_{\mathrm{s}}$ die periode van die sinusvormige sein is, gegee deur

$$
T_{s}=\frac{2 \pi}{\omega_{s}}
$$

Soos verwag kan word, bestaan daar 'n omgekeerde eweredige verwantskap tussen $\sigma\left(\Delta t_{p}\right)$ en die sein/ruisverhouding, wat soos volg beskryf kan word:

$$
R_{S / R}=\frac{V}{\sqrt{2} \sigma(n)}
$$

Teen die agtergrond hierbo geskets, kan die volgende metodes vir die onttrekking van die benodigde inligting aangebied word:

\subsection{Metode (a)}

Dit is die mees elementêre metode en berus op die meting van die tyd tussen twee opeenvolgende positiewe nulkruisings van die sein, met die volgende resultaat:

$$
\begin{aligned}
T_{a} & =t_{p+1}-t_{p} \\
& =(p+1) T_{s}+\Delta t_{p+1}-p T_{s}-\Delta t_{p} \\
& =T_{s}+\Delta t_{p+1}-\Delta t_{p}
\end{aligned}
$$

waaruit die variansie volg:

$$
\sigma^{2}\left(T_{a}\right)=\sigma^{2}\left(\Delta t_{p+1}\right)+\sigma^{2}\left(\Delta t_{p}\right)
$$

Aangesien $\Delta t_{p+1}$ en $\Delta t_{p}$ ongekorreleerd is, is

$$
\sigma\left(T_{\mathrm{a}}\right)=\sqrt{2} \sigma\left(\Delta t_{p}\right)
$$

\subsection{Metode (b)}

Die tyd tussen $t_{0}$ en $t_{N s}$ word gemeet en gedeel deur die aantal positiewe nulkruisings $\left(N_{s}\right)$ om 'n gemiddelde waarde van die seinperiode te gee.

$$
\begin{aligned}
\mathrm{T}_{\mathrm{h}} & =\left[t_{N_{s}}-t_{0}\right] / N_{s} \\
& =\left[N_{s} T_{s}+\Delta t_{N_{s}}-\Delta t_{0}\right] / N_{s} \\
& \left.=T_{s}+\left[\Delta t_{N_{s}}-\Delta t_{0}\right]\right]_{N_{s}}
\end{aligned}
$$

Aangesien $\Delta t_{N s}$ en $\Delta t_{0}$ ongekorreleerd is, volg dat

$$
\sigma\left(t_{b}\right)=\sqrt{2} \sigma\left(\Delta t_{p}\right) / N_{s}
$$

Hoe meer seinperiodes dus in aanmerking geneem word, hoe akkurater word die metode, aangesien die standaardafwyking eweredig is aan $I / N_{s}$.

\subsection{Metode (c)}

Hierdie metode benut alle gemete tydwaardes van positiewe nulkruisings om $T_{s}$ te estimeer. Die waardes word verwerk met behulp van die metode van kleinste kwadrate. ${ }^{2}$ Vir 'n stel van gemete waardes (van $t_{p}$ vir $p$ vanaf 0 tot $N_{s}$ ) word 'n stel van $\left(N_{s}+I\right)$ vergelykings verkry:

$$
t_{0}+p T_{c}=p T_{s}+\Delta t_{p}, \quad p=0,1, \ldots, N_{s} .
$$

Die oplossing van hierdie stel gee die waardes van $T_{c}$ en $\sigma\left(T_{c}\right)[2]$.

\section{IMPLEMENTERING VAN DIE VERWERKINGS- TEGNIEKE}

Metode (a) is ' $n$ triviale oplossing vir die meetprobleem en sal nie verder hanteer word nie. Geskikte apparatuur en programmatuur is ontwikkel vir die implementering van metodes (b) and (c). Dit sal nie in besonderhede bespreek word nie, maar die blokdiagram van figuur 2 illustreer die stelselbeginsels.

Die saamgestelde sein beskryf in vergelyking (1) word verkry deur noubandruis te sommeer met 'n sinusvormige sein afkomstig van 'n hoè stabiliteit 10MHz-bron (frekwensie-stabiliteit van 1 deel in $10^{6}$ ). Die $10 \mathrm{MHz}$-sein word verdeel deur ' $n$ faktor van $2^{13}(8192)$ en deur 'n onderlaatfilter gestuur, wat resulteer in 'n sinusvormige sein met 'n periode $T_{s}=819,2 \mu \mathrm{s}$. Die saamgestelde sein word dan die inset tot die nulkruisingsdetektor en ontbonsingsbaan, wat tot gevolg het 'n reeks pulse wat die positiewe nulkruisings verteenwoordig. Die tye waarop die nulkruisings voorkom, word bepaal deur pulse vanaf ' $n$ hoë stabiliteit klokfrekwensiegenerator $\left(5\right.$ dele per $\left.10^{6}\right)$ te tel. Die data word via 'n geskikte koppelvlak in die rekenaar ingelees en met behulp van die betrokke algoritmes verwerk.

Die implementering van metodes (a) en (b) word vervolgens bespreek.

\subsection{Metode (b)}

Hierdie metode bereken bloot die gemiddelde waarde van die seinperiode oor ' $n$ gekose aantal periodes $\mathrm{N}_{\mathrm{s}}$. Dit word gerealiseer deur die tyd tussen positiefgaande nulkruisings 


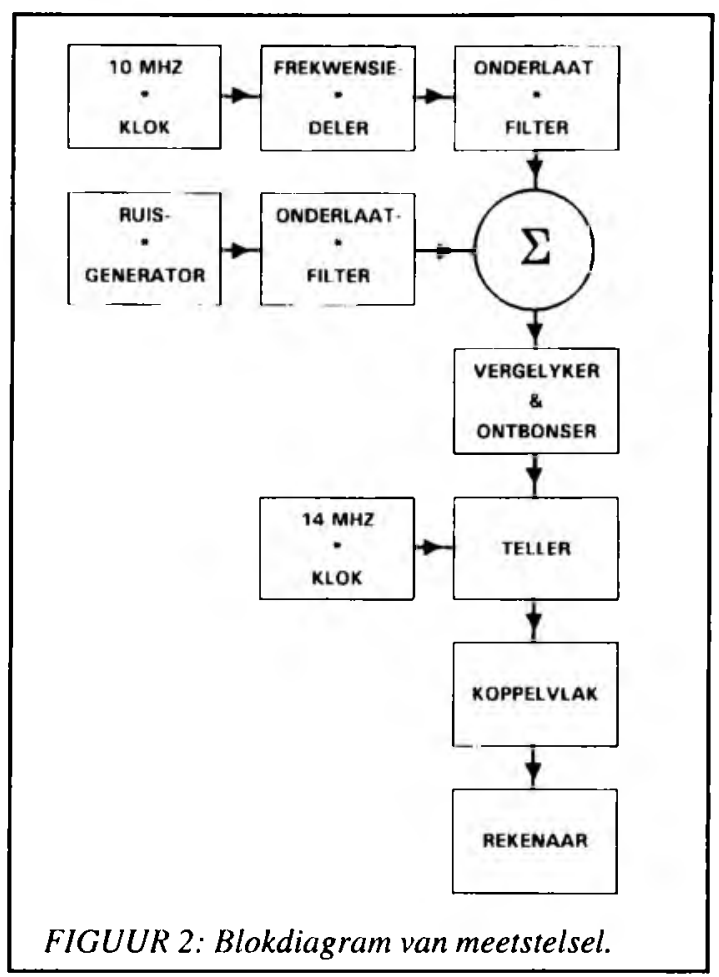

by tye $t_{0}$ en $t_{N_{s}}$ te meet en dan te deel deur die aantal periodes $N_{s}$. Die resultaat is $T_{b}$, wat die beste waarde is, met hierdie metode, vir die seinperiode $T_{s}$. Hierdie tegniek is toegepas vir verskillende waardes van $N_{s}$ vanaf 100 tot 1024. Die waarde van $\sigma\left(T_{b}\right)$ is bereken vanuit 'n stel van $T_{b}$, waardes wat verkry is deur die proses 1024 keer te herhaal by die verskillende waardes van $N_{s}$.

\subsection{Metode (c)}

Hierdie metode benut alle beskikbare data, dit is alle tye waarop positief-gaande nulkruisings voorkom. Die waardes van hierdie tye vorm 'n ry met punte wat nie eweredig versprei is nie, soos gedefinieer in vergelyking (3). Hierdic datapunte kan grafies teenoor die aantal nulkruisings voorgestel word soos getoon in figuur 3.

Met behulp van die metode van kleinste kwadrate word ' $n$ reguit lyn gepas aan die eksperimentele data. $T_{c}$, wat die afskatting van $T_{s}$ is, kan verkry word vanuit die helling van die reguillyn, wat gegee word deur ${ }^{3}$ :

$$
\frac{\Delta y}{\Delta x}=\frac{\sum_{n=1}^{N_{s}}\left(x_{i}-\bar{x}\right)\left(y_{i}-\bar{y}\right)}{\sum_{n=1}^{N_{s}}\left(x_{i}-\bar{x}\right)^{2}}
$$

\section{RESULTATE}

\subsection{Gemiddelde en standaardafwyking vir metodes (b) en (c)}

Metodes (b) en (c) is geimplementeer vir sein/ruis-verhoudings van 5 en 10 respektiewelik. Tabel 1 toon die waardes van gemiddeldes en standaardafwykings soos vanuit die eksperimentele data bereken.

\subsection{Die invloed van meettyd}

Die aantal positiefgaande nulkruisings waarvan die tyd van voorkoms bepaal word, bepaal die meettyd. Figuur 4 toon

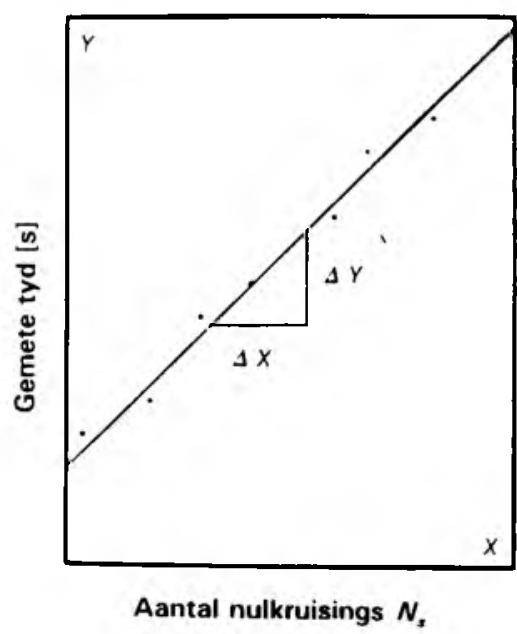

FIGUUR 3: Tyd van voorkoms versus aantal nulkruisings (nie volgens skaal).

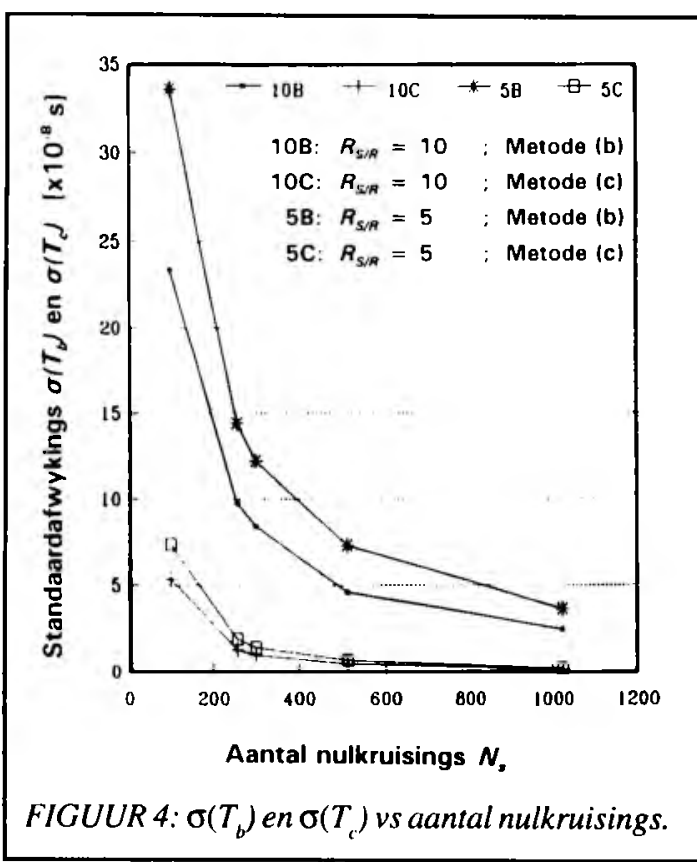

TABEL 1 Resultate vir metodes (b) en (c)

\begin{tabular}{|c|c|c|c|c|}
\hline $\boldsymbol{R}_{S / R}$ & $\boldsymbol{T}_{b}(\mu \mathbf{s})$ & $\sigma\left(\boldsymbol{T}_{b}\right)(\mu \mathbf{s})$ & $\boldsymbol{T}_{c}(\mu \mathbf{s})$ & $\sigma\left(\boldsymbol{T}_{\partial}(\mu \mathbf{s})\right.$ \\
\hline 10 & 819,181 & $2,4 \times 10^{-3}$ & 819,2004 & $1,5 \times 10^{-2}$ \\
\hline 5 & 819,179 & $3,6 \times 10^{-3}$ & 819,2003 & $2,2 \times 10^{-2}$ \\
\hline
\end{tabular}

LET WEL : Die waardes in tabel 1 is verkry vir $N_{s}=$ 1024 en $T_{s}=819,2 \mu \mathrm{s}$.

die invloed van meettyd op die resolusie van die meetproses. Dit is opmerklik dat by laer waardes van meettyd die tempo van verbetering van resolusie beter is.

\section{GEVOLGTREKKINGS}

Die probleem van bepaling van frekwensie of periode van ' $n$ sinusvormige sein met ruis binne ' $n$ beperkte tyd, is ondersoek. 'n Tipiese voorbeeld is die presessiesein by die protonmagnetometer. Meetfoute word in hierdie geval ingevoer as gevolg van fasemodulasie te wyte aan 'n additiewe ruiskomponent. 
Twee metodes is geïmplementeer met geskikte apparatuur en gepaste programmatuur. Metode (b) benut slegs 'n gedeelte van die beskikbare data om die gevraagde inligting af te skat, terwyl metode (c) alle beskikbare inligting aanwend (dit is al die tydinligting ten opsigte van die positiefgaande nulkruisings).

Die resultate toon dan ook, soos verwag kon word, dat metode (c), gebaseer op die metode van minimum kwadrate, superieur is teenoor metode (b). Vir 'n gegewe meettyd sal metode (c) 'n kleiner meetfout bevat in vergelyking met metode (b).

\section{G.P. HANCKE}

Departement Elektriese en Elektroniese Ingenieurswese, Universiteit van Pretoria, Pretoria, 0002

\section{LITERATUURVERWYSINGS}

1. Hancke, G.P. (1990). The Optimal Frequency Estimation of a Noisy Sinusoidal Signal, IEEE Trans. Instrum. Meas., vol. 39, no. 6, 843 $-846$.

2. Jackson, D. (1930). The Theory of Approximation. Providence, RI Amer. Math. Soc. Colloquium Publ. Ser., vol. XI, chapter III.

3. Giordano, A.A. \& Hsu, F.M. (1985). Least Square Estimation with Application to Digital Signal Processing. (New York: Wiley). 